\title{
Can One Undergraduate Course Increase Cross-Cultural Competence?
}

\author{
Lois Spitzer \\ School of Education, Stockton University \\ 101 Vera King Farris Dr., Galloway, New Jersey 08205, United States \\ Tel: 1-609-652-4629Ｆax: 1-609-626-5528Ｅ-mail: lois.spitzer@stockton.edu
}

Received: April 14, 2015 Accepted: May 14, 2015 Published: May 20, 2015

doi:10.5296/jei.v1i1.7444 URL: http://dx.doi.org/10.5296/jei.v1i1.7444

\begin{abstract}
The majority of students who took this general education undergraduate course in developing cross-cultural understanding at a state college in the northeastern United States reported that their level of cross-cultural competence and global awareness increased by the end of the course. The primary course objective was to help students better understand their own cultural roots and become more globally aware of other cultural groups. This limited study revealed that this one undergraduate college course was successful in increasing cultural self-awareness, cross-cultural competence, and global awareness among the students who took the course. In addition, it points to the need for more courses to be added to college curricula and for more statistically significant studies to be conducted.
\end{abstract}

Keywords: Cross-cultural awareness, Cross-cultural competence, Cultural identity, Global awareness, Cultural awareness, Cultural self-awareness

\section{Introduction}

While much has been written about the need for cross-cultural competence in the health sciences, educational and related service fields, almost nothing has been written about how institutions of higher education can increase competence in this area for undergraduates studying to be professionals in fields other than health sciences or education. In addition, most research focuses on the achievement of these competencies through international study or travel. Indeed, most colleges and universities today have study abroad programs, intensive English programs on campus, and international student clubs and activities. But what is being offered to increase the cultural awareness and cross-cultural competence of domestic students who cannot travel abroad or have international experiences? Colleges and universities must begin considering the inclusion of courses in the college curricula on cross-cultural understanding to address the imperative for undergraduates to increase their global awareness to be competitive in all professional fields. Also, research in this area of educational options other than study abroad experiences needs to be carried out to determine the effectiveness of 
these options. The limited study presented in this article is hopefully a start to this kind of research to meet this need.

\section{Cross-Cultural Competence and Cultural Self-Awareness}

Although there is no one definitive definition of cross-cultural or intercultural competence, Cross et al. (1989) explored this concept in the context of the health care industry and their definition is foundational to that field: "Cultural competence is a set of congruent behaviors, attitudes, and policies that come together in a system, agency or among professionals and enable that system, agency or those professions to work effectively in cross-cultural situations" (as quoted in Bennett, 2011: p. 1). In the same vein, the Intercultural Communication Institute offers this definition of intercultural competence "...[intercultural competence] is a set of cognitive, affective and behavioral skills and characteristics that support effective and appropriate interaction in a variety of cultural contexts" (Bennett, 2011: p. 1). Dillard et al. (1992), also working in the health field, offer yet another similar definition of cultural competence as being: "....an awareness of, sensitivity to and knowledge of the meaning of culture. Awareness is defined as having knowledge and being well-informed, while sensitivity is stated as being open to and having a readiness to respond (as quoted by Cheung, Shah, \& Muncer, 2002: p. 543).

Cultural self-awareness as a prerequisite to understanding those from different cultures is self-evident. "Cultural awareness becomes central when we have to interact with people from other cultures. People see, interpret and evaluate things in a different ways. What is considered an appropriate behavior in one culture is frequently inappropriate in another one. Misunderstandings arise when I use my meanings to make sense of your reality" (Quappe \& Cantatore, 2005: p. 1). Rose (2003) offers a similar explanation of the relationship of cultural self-awareness and intercultural communicative competence as follows: "Intercultural communicative competence is an attempt to raise students' awareness of their own culture, and in so doing, help them to interpret and understand other cultures" (p.1).

Musil (2006), writing about higher education adds that in addition, there are goals that should be addressed to cultivate the intercultural awareness of our college graduates. She states that our institutional goals should include those that seek to prepare graduates who "...understand diverse cultures and the complexities of individual identities in a transnational environment" and "...can communicate across diverse cultures" (p. 6). Bhawuk and Brislin (1992) and Caleb (1998) point out the need to prepare students to develop leadership skills in intercultural competence and Deardoff (2009: p. 67) asserts that future leaders must have a "...mind-set, hear-set, and skills-set that can carry across cultural boundaries".

In response to the call to increase the cultural awareness of our students, some college courses have been created to meet this demand. Institutions have made a commitment to redesign their curricula to enhance students' intercultural skills. However, Musil (2006) points out that: "There is little or no evidence that students are provided with multiple, robust, interdisciplinary learning opportunities at increasing levels of intellectual challenge to ensure that they acquire the global learning professed in mission statements"(p. 2).

Colleges and universities need to discover creative ways to infuse their curricula with courses that will amend this situation in fields where this need is not currently being met. Although much has been written about how cross-cultural competence and cultural sensitivity can be infused into the health science curriculum, little has been written about the need to infuse this material into the general education undergraduate curriculum. Can one college course in developing cross-cultural competence help students become more culturally aware and thus 
better prepared to enter the twenty-first century workforce? To begin to answer this question, this author created a general studies course entitled Developing Cross-Cultural Understanding and offered this course at the institution where the author is a faculty member of the School of Education.

\section{The Course: Developing Cross-Cultural Understanding}

The proposal for this introductory general education course on cultural awareness aimed at freshmen and sophomores included as its description: "...to expose students to the beliefs and practices of different cultures, the acquisition of a second language and culture, cross-cultural communication, the role of home and community, and accommodations to foster the language and culture acquisition of people from other cultures" (Spitzer, GEN 1430 syllabus, fall 2012).

This course required students to explore and make oral presentations based on their own cultural heritage and reflect upon the values and traditions of their own upbringing. By doing this, they learned about themselves and the experiences, beliefs and practices of their classmates from other cultural backgrounds. In addition to exploring their own cultural backgrounds and identities, students listened to presentations made by faculty members from disciplines across the curriculum relating their experiences of discovering their cultural identities.

As rationale for the course, demographic information about our state (New Jersey) was offered to the General Studies committee of the college (New Jersey Fact Sheet, 2013):

$>$ In 2011, the foreign born represented 21.5 percent of New Jersey's total population.

$>$ Of the total immigrant population in New Jersey, 26.6 percent entered during the 1990s, and 36.4 percent entered in 2000 or later.

$>$ At the national level, the foreign-born population represented 13.0 percent of the total population in 2011, compared to 11.1 percent in 2000 and 7.9 percent in 1990.

The above statistics record the immigrant population in New Jersey. New Jersey has long been the home to generations of immigrants who came to this country over the last two hundred years. This state's culturally (and linguistically) diverse population demands students at any college to be ready to work and communicate with individuals from different cultures. This course exposed students to the topics of cultural sensitivity, cross-cultural communication, the acculturation process, and the cultural resources that would help them be more effective living and working with individuals from all cultural backgrounds.

The proposed topics for this course included demographic trends in the US (and in students' own towns or cities), understanding other cultural traditions (their own and others' from presentations and projects), culture shock and the process of acculturation (recorded experiences of respondents to student-created surveys), building relationships across cultures and cross-cultural communication (reflective papers), the acquisition of language and culture (lectures, discussions, and presentations), educational, linguistic and cultural accommodations (lectures, discussions, and presentations), and moving from fear toward tolerance and understanding (documented in final paper).

The specific learning objectives of this course were created to expand the students' knowledge of: demographic trends in the US, traditions and values across cultures, cultural products, practices, perspectives, and communities, an appreciation for spoken language, oral culture, 
printed language and literate culture, culture shock and the process of acculturation, aspects of cross-cultural communication, the relationship of identity, language, and culture, and educational, linguistic and cultural accommodations to enhance cross-cultural communication.

The following class assignments were created to meet the class objectives: 1) journal assignments based on readings which explore cultural characteristics and values, 2) reactions to presentations made to class by professors in the college from other cultural backgrounds, 3 ) a cultural self-identification oral presentation, 4) a final project including the documentation of a service learning project and the creation of a survey and administration of interviews to at least three people who are part of an ethnic group different than the student's and who were born outside this country, and 5) a final reflective essay explaining what had been learned in the course and how this information could be used in other courses, in their personal/social lives, and in their future careers

\subsection{Cultural Self-Identification Oral Presentation}

Students were required to make class presentations and complete a written paper about the beliefs, traditions, values, and ethics associated with the culture(s) with which they identified. This project required that students interview family members about their past and do genealogical work to discover their families' history and culture. The following questions had to be addressed in the paper and the presentation:

1) When/how did you family arrive in the US? From what country(s) did they come?

2) Is one culture dominant over another in your family?

3) What foods are traditional in your home? Do they belong to one or another culture? (What is their significance, if any?) Did you eat these food often at home?

4) What are the celebrations, ceremonies, rituals, or holidays that your family celebrate?

5) Does anyone in your family speak a different language? (If so, what language(s)?)

6) Were there any sociocultural factors that made you different from your friends, classmates, neighbors, or others in your community? (e.g., socioeconomic status, education level, living arrangement with other relatives, or worldview)

7) Share one piece of advice that has been handed down through your family that reflects the values held by your ancestors. Does it reflect a cultural, religious or individual view?

\subsection{Final Project and Service Learning Component}

Service learning played a major role in the class experience. Students needed to complete a final service-learning project whose focus was to document personal experiences with culture shock and acculturation. Students were instructed to carry out service in a place where they would be working with people from cultural groups other than their own. The requirements included the creation of a survey and collection of responses from at least 3 individuals (not friends or family members) who were either born outside this country (i.e., first generation immigrants) or the first generation of their family in this country (second generation immigrants). Students were instructed to compare their respondents' experiences with what researchers say is the "typical" pattern of acculturation. Service learning enabled students to engage with the community while gaining valuable hands-on experience, and provided a way to apply the theories and knowledge they were exposed to in class to their service-related activities. 


\subsection{Final Reflective Essay}

Students were asked to complete a final reflective essay explaining what they felt they had learned in the course in regard to cultural competence, cultural self-awareness and global awareness, and how this information could be used in other academic courses, in their personal and social lives, and in their future careers.

\section{Research Design and Tool}

In the fall of 2012, the 35 participants in this study were students in this undergraduate class entitled Developing Cross-Cultural Understanding, which was composed of a mixture of freshmen and sophomores, males and females, all under 25 years of age. They were asked to take a pre-course survey at the beginning of the semester (second class) and a post-course survey on the last day of class. Thirty-five students participated in the survey and consent forms for all participating students were obtained. They were also instructed that the survey was anonymous.

\section{MyCAP (My Cultural Awareness Profile): Your Journey Towards Cultural And Global} Awareness (Marx \& Moss, 2011) was the survey tool selected for use in this project. It was selected because of its correlation to the specific goals of the class. In the introduction to the survey, Marx and Moss identified four dimensions in which gaining knowledge, understandings, and skills are required for cultural and global awareness:

\section{1) Exploring the Global World (Global Perspective)}

\section{2) Learning about Different Cultures (Cultural Awareness)}

\section{3) Knowing Ourselves as Cultural (Perspective Consciousness)}

\section{4) Communicating across Cultural Differences (Intercultural Communication)}

The authors of MyCap, Marx and Moss (2011), go on to state:

Each of us is at a different point in our journey to becoming culturally and globally aware. On our journeys, it is important to reflect on where we are at this point in our development and make plans for how we can move forward as we gain the knowledge, understandings, and skills necessary to become a global citizen. The Cultural Awareness Profile (MyCAP) is a self-reflection tool that provides you with the opportunity to consider your current levels of knowledge, skills, and understandings across these dimensions (p. 1).

MyCAP contains statements that require the student to choose one of the given responses. There is an open-ended question at the end of the survey that gives the respondent the opportunity to engage in written reflections. The statements are designed to help the respondent identify her/his current knowledge and understanding. The directions instruct the respondent to be as honest and open in answering and that there are no right answers in this self-reflection, only honest ones. Further, the authors instruct the respondent to:

...use your MyCAP with an instructor or mentor to reflect on each of the four dimensions of cultural and global awareness. As you learn about yourself and consider your current knowledge, understandings, and skills, you will work to create an action plan of steps you can take in your life and coursework toward your continued cultural and global learning (p. 1).

The entire class ( $\mathrm{n}=35$ students) was administered the survey at the beginning and end of the course. The data from both surveys was then compared to measure the growth in the students' (perception of their) cultural awareness. (The survey tool can be found in Appendix 2.) 
5. Results (See data charts with the pre-and post course responses to each statement in the survey in Appendix 1)

In response to the first fifteen statements, students were instructed to circle the responses that best represented their views. There were two open-ended questions at the end of the post-course survey: 1) In a few words, please reflect on the most important thing(s) you learned in this course, and 2) Did you learn what you hoped you would?

\subsection{Interpretation of Results}

In response to statement \#1 (I am knowledgeable about global and international issues), 55\% of the students somewhat agreed in the pre-course responses and 96\% somewhat agreed in the post-course responses. Change from pre-course to post-course responses was $+41 \%$. This clearly indicates that almost twice as many students felt they became knowledgeable about global and international issues in the time between the pre- and post surveys.

The statement I read or watch international newspapers, TV programs, and/or movies (\#2) showed that $51 \%$ of the students agreed with this statement sometimes in the pre-course survey, whereas the post-course responses showed that $56 \%$ of the students sometimes agreed with it. A slightly greater percent $(+4 \%)$ of students reported reading about or watching news and/or movies in the time between the pre- and post surveys.

In response to the statement Globalization has impacted my life (\#3), 39\% of the students somewhat agreed in the pre-course survey while $67 \%$ of the students somewhat agreed in the post-course survey. The change from pre-course to post-course survey indicated an increase of $+28 \%$ indicating solid growth in the perception that globalization is important to them.

In response to the statement I consider how choices I make in my life might have a global impact (\#4), 39\% of the students answered sometimes in the pre-course survey while $56 \%$ answered sometimes in the post-course survey showing a $+17 \%$ change from pre-course to post-course responses. Again, the course helped many students to acknowledge that they could make an impact on the global environment.

An increase in the number of students who somewhat agreed with the statement When I meet new people, I try to learn about their cultural backgrounds (\#5) from $70 \%$ in the pre-course responses to $89 \%$ in the post-course responses indicating that $19 \%$ more of the students expressed interest in other people's cultural backgrounds in the time between the pre- and post-surveys.

In response to statement \#6 (Talking about common cultural characteristics is different from stereotyping), pre-course responses showed that $88 \%$ of the students somewhat agree while the post-course responses showed $93 \%$ of the students somewhat agree. The $+5 \%$ change showed a slight increase in the understanding that there is a difference between cultural characteristics and stereotypes.

The statement Culture is more about traditions, celebrations, and history than about core values (\#7) showed that $46 \%$ of the students somewhat agreed with this statement in the pre-course survey, whereas the post-course responses showed that $41 \%$ of the students somewhat agreed with it. These responses indicated that students reported a slight decrease $(-5 \%)$ in the understanding of what culture is at a deeper level.

Cultural self-awareness increased by $+9 \%$ as shown in the response to statement \#8 (I consider myself as being part of a particular culture) from $61 \%$ of the students somewhat 
agreeing in the pre-course responses to $70 \%$ of the students somewhat agreeing in the post-course responses.

Responses to My cultural identity does not really influence how I perceive the world and how I behave (\#9) changed from $42 \%$ somewhat agreeing in the pre-course responses to $33 \%$ somewhat agreeing in the post-course responses. These results show that fewer students believed that their cultural identity influences how they perceived the world in the time between the pre- and post-surveys.

Students reporting sometimes feeling like a cultural outsider (\#10: I have been in situations where I felt like a cultural outsider) increased from $42 \%$ to $60 \%$ or $+18 \%$ in the time between the pre- and post-surveys.

Slightly fewer $(-4 \%)$ of the students responded that they sometimes talk about their beliefs, values and traditions (\#11: I hardly ever talk about beliefs, values, and traditions) in the post-course survey ( $30 \%$ pre-course survey to $26 \%$ post-course survey).

Eighty-eight percent $(88 \%)$ of the students responded in the pre-course survey that they somewhat agree to statement \#12: I am comfortable talking with people from other cultural groups, while $100 \%$ of the students somewhat agree in their post-course responses indicating $\mathrm{a}+12 \%$ increase in their comfort level talking to people from other cultural groups.

In response to statement \#13: In any job situation, it is helpful to learn about the cultural background of my co-workers, $61 \%$ of the students somewhat agreed in the pre-course survey while $93 \%$ somewhat agreed with this statement. The number of students acknowledging the helpfulness of learning about other co-workers increased by approximately one-third $(+32 \%)$.

There was a slight increase $(+8 \%)$ in the number of students who sometimes noticed body language is culturally specific (statement \#14: I notice that people from other cultures use different gestures and body language when they talk) from $85 \%$ in the pre-course responses to $93 \%$ in the post-course responses.

Fifty-two percent (52\%) of the students indicated that they sometimes adjust their communication styles depending on whom they are talking to (statement \#15: I adjust my communication styles depending on whom I am talking to) in the pre-course survey while $78 \%$ of the students had this response in the post-course survey. This indicated that $+26 \%$ more of students acknowledged that they adjusted their communication styles when talking to people from other cultures between the time of the pre- and post-survey.

\subsection{Summary of Results}

The comparison of answers in the pre-course survey and the post-course survey indicate that as a result of taking this class:

> $41 \%$ more students felt they gained knowledge about global and international issues (statement \#1).

$>4 \%$ more students report an increase in the amount of time they read or watch international newspapers, TV programs, and/or movies (statement \#2).

$>28 \%$ more students felt that globalization has impacted their lives than at the beginning of the course (statement \#3).

$>17 \%$ more students reported an increase in the amount of time they read or watch international newspapers, TV programs, and/or movies (statement \#4). 
$>19 \%$ increase in the number of students who said they tried to learn about the cultural backgrounds of new people they meet (statement\#5).

$>5 \%$ increase in the number of students who felt that talking about common cultural characteristics is different from stereotyping (statement \#6).

$>5 \%$ fewer students felt that culture is more about traditions, celebrations, and history than about core values (statement \#7).

> $9 \%$ more students considered themselves as being part of a particular culture (statement $\# 8)$.

* $\quad 9 \%$ fewer students feel that their cultural identity does not really influence how they perceive the world and how they behave (statement \#9).

* $\quad 18 \%$ more students felt as though they had been in situation where they felt like a cultural outsider (statement \#10).

> $4 \%$ fewer students answered that they hardly ever talk about beliefs, values, and traditions (statement \#11).

$>12 \%$ more students felt comfortable talking with people from other cultural groups (statement \#12).

$>32 \%$ more students felt that it is helpful to learn about the cultural background of their co-workers in a job situation (statement \#13).

$>8 \%$ more students notice that people from other cultures use different gestures and body language when they talk (statement \#14).

$>26 \%$ more students say that they adjust their communication styles depending on whom they are talking to (statement \#15).

All of the statements in the post survey but two (statements \#9 and \#10, marked with an asterisk) indicated a positive increase in cultural awareness, cross-cultural understanding, and global awareness. Statement \#9 might have yielded converse results because of its ambiguous construction and the responses to statement \#10 could have been a result of their new awareness of being part of a cultural group.

The two open-ended questions on the post survey also yielded positive results. All 29 responses to the first open-ended question (In a few words, please reflect on the most important thing(s) you learned in this course) were positive indicating that the students who responded to this question thought they had increased their cross-cultural competence, global awareness and cultural self-awareness as a result of taking this class. The second open-ended question (Did you learn what you hoped you would?) yielded 24 positive responses indicating that the students felt they had learned what they hoped they would from the experience of taking the class.

\subsection{Discussion of Results}

Based on the results of the surveys, it can be concluded that at the completion of this course in developing cross-cultural competence, students reported they felt that their knowledge about cross-cultural competence had increased (as evidenced by pre- and post responses to statements \#5, \#6, \#7, \#12, \#14 and \#15). In addition, their global awareness had increased (as evidenced by the pre- and post responses to statements \#1, \#2, \#3 and \#4). Finally, their 
response to statement \#8 indicated they felt their cultural self-awareness had increased. The responses to the open-ended questions also indicated that students who responded to these questions felt that their cross-cultural competence, global awareness and cultural self-awareness had increased and they had gained from the course what they hoped they would.

\section{Conclusion: Limitations of this Study and Implications for Higher Education}

This was a very limited study based on one class with 35 students, which is admittedly an extremely small sample, and therefore not statistically significant. However, these findings present positive findings and point to the potential benefits of courses in cultural self-awareness and cross-cultural understanding. This one college class affected the students enrolled in it; their perceptions about cultural awareness increased. Perhaps more classes in a student's program would result in an even bigger gain in this important area. Any positive change in cultural awareness is welcomed, but educators dedicated to equipping students for a globalized world should not be satisfied with only one course addressing this critical topic; this topic should be integrated across the curriculum. The positive findings of this small study on the effect of cultural self-awareness on cultural competence beg for more statistically significant studies in this area and, if with the completion of more studies it is found that cultural self-awareness does have a statistically significant positive impact on cultural competence, it is imperative that courses such as these should be added to the curriculum and required of undergraduates in institutions of higher learning.

\section{References}

Bennett, J. (2011). Developing Intercultural Competence for International Education Faculty and Staff. Presentation delivered at the AIEA Conference, February 22, 2011. Retrieved April 9, 2015, from http://www.intercultural.org/documents/competence_handouts.pdf

Bhawuk, D. P., \& Brislin, R. (1992). The measurement of intercultural sensitivity using the concepts of individualism and collectivism. International Journal of Intercultural Relations, 16(4), 413-436. As cited in Fabregas Janeiro, M. G., Lopez Fabre, R., \& Nuno de la Parra, J. P. (2014). Building Intercultural Competence through Intercultural Competency Certification of Undergraduate Students. Journal of International Education Research, 10(1), 16.

Cheung, Y., Shah, S., \& Muncer, S. (2002). An exploratory investigation of undergraduate students' perceptions of cultural awareness. The British Journal of Occupational Therapy, 65(12), 543-550. http://dx.doi.org/10.1177/030802260206501203

Cross, T., Bazron, B., Dennis, K., \& Isaacs, M. (1989). Towards A Culturally Competent System of Care (Vol. I). Washington, DC: Georgetown University Child Development Center, CASSP Technical Assistance Center.

Deardoff, D. K. (Ed.). (2009). The sage handbook of intercultural competence. Thousand Oaks. CA: Sage. As cited in Fabregas Janeiro, M. G., Lopez Fabre, R., \& Nuno de la Parra, J. P. (2014). Building intercultural competence through intercultural competency certification of undergraduate students. Journal of International Education Research, 10(1), 16.

Dillard, M., Andonian, L., Flores, O., Lai, L., MacRae, A., \& Shakir, M. (1992). Culturally competent occupational therapy in a diversely populated mental health setting. American Journal of Occupational Therapy, 46, 721-26. http://dx.doi.org/10.5014/ajot.46.8.721

Marx, H. A., \& Moss, D. M. (2011). MyCAP (My Cultural Awareness Profile). Washington, 


\section{Macrothink}

D.C.: NAFSA (Association of International Educators). Retrieved April 15, 2015, from http://www.nafsa.org/mycap

Musil, C. M. (2006). Assessing Global Learning: Matching Good Intentions with Good Practice. Washington, D.C.: AAC\&U (American Association of College and Universities).

New Jersey Fact Sheet. (2013). Washington, D.C: Migration Policy Institute. Retrieved April 15, 2015, from http://www.migrationinformation.org/datahub/state.cfm?ID=NJ\#8

Quappe, S., \& Cantatore, G. (2003). What is Cultural Awareness, anyway? How do I build it? Retrieved April 15, 2015, from http://www.culturosity.com/pdfs/What $\% 20$ is $\% 20$ Cultural\%20 Awareness.pdf

Rose, C. (2003). Intercultural Learning. British Council on Education. Retrieved April 15, 2015, from https://www.teachingenglish.org.uk/article/intercultural-learning-1

\section{Appendix}

Appendix 1. Data charts with the pre- and post course responses to each statement in the survey followed by responses to the open-ended questions added to the post-course survey
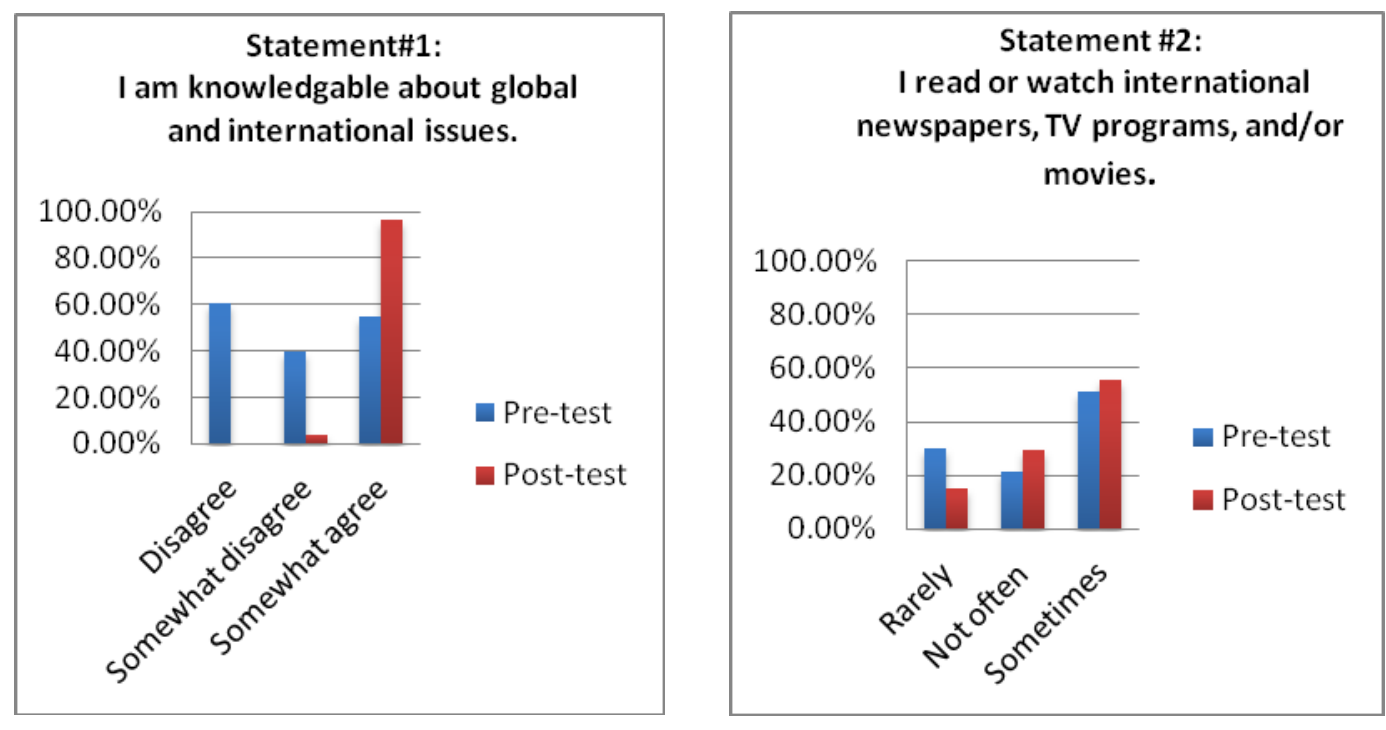

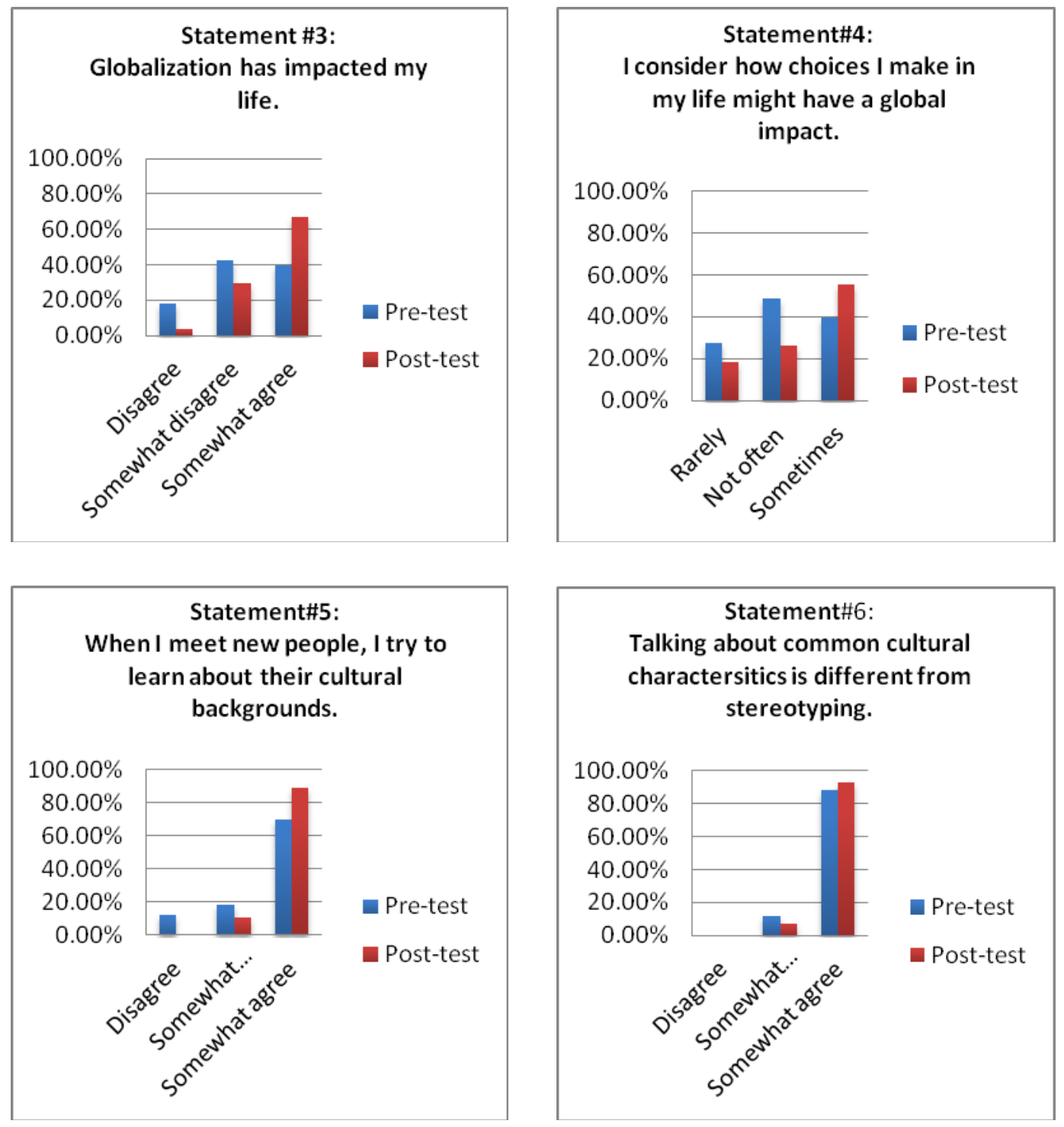

Statement\#7:

Culture is more about traditions, celebrations, and history than about core values.
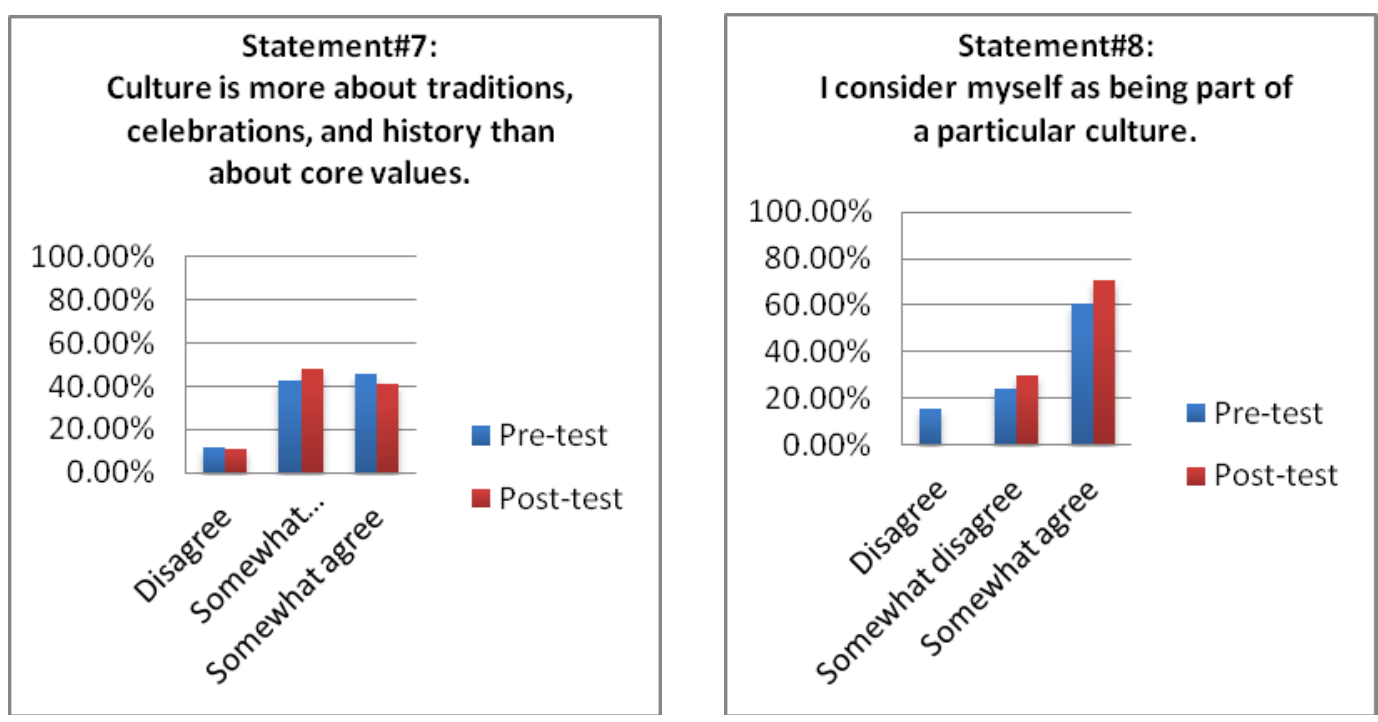
Statement \#9:

My cultural identity does not really influence how I perceive the world and how I behave.

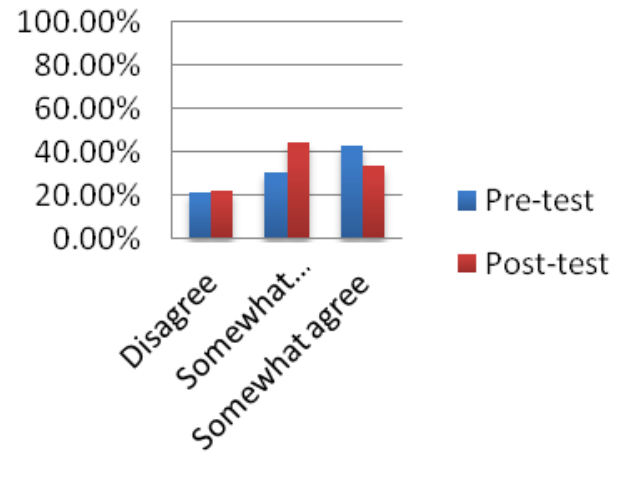

\section{Statement \#11:}

I hardly ever talk about cultural beliefs, values, and traditions.

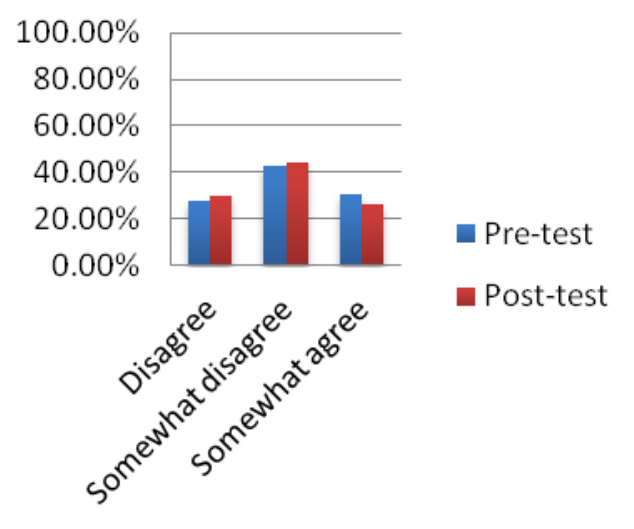

Statement \#13:

In any job situation, it is helpful to learn about the cultural background of my co-workers.

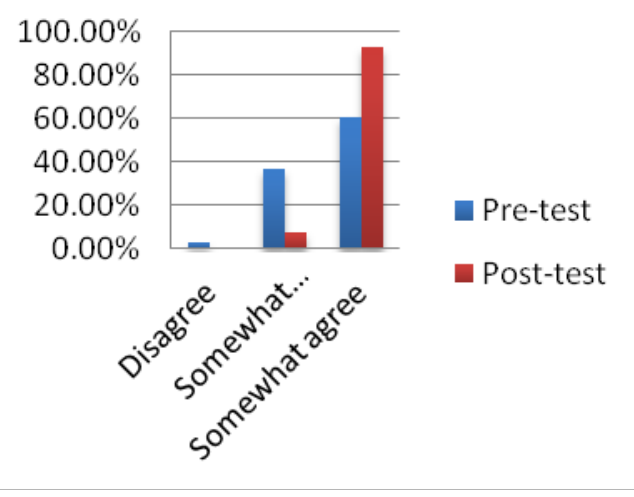

Statement\#10:

I have been in situations where I felt like a cultural outsider.

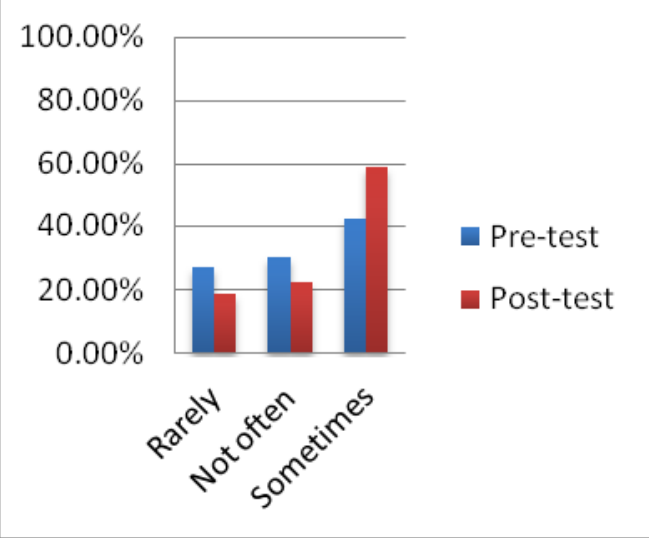

Statement \#12:

I am comfortable talking with people from other cultural groups.

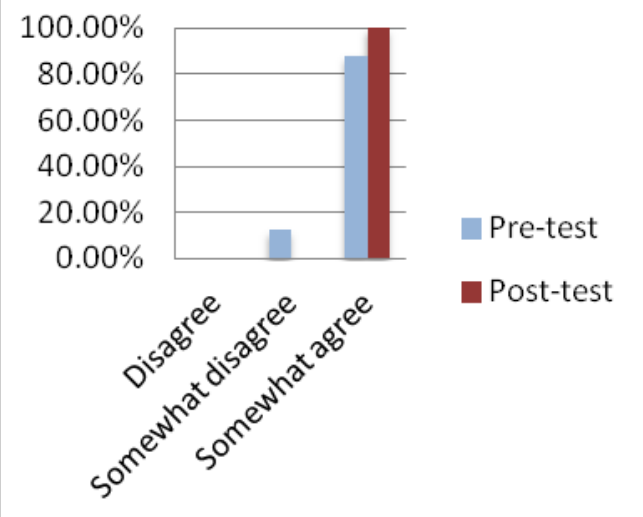

Statement \#14:

I notice that people form other cultures use different gestures and body lanaguge when they talk.

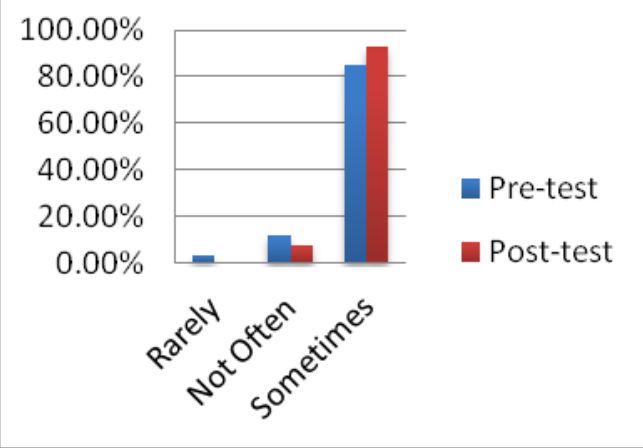




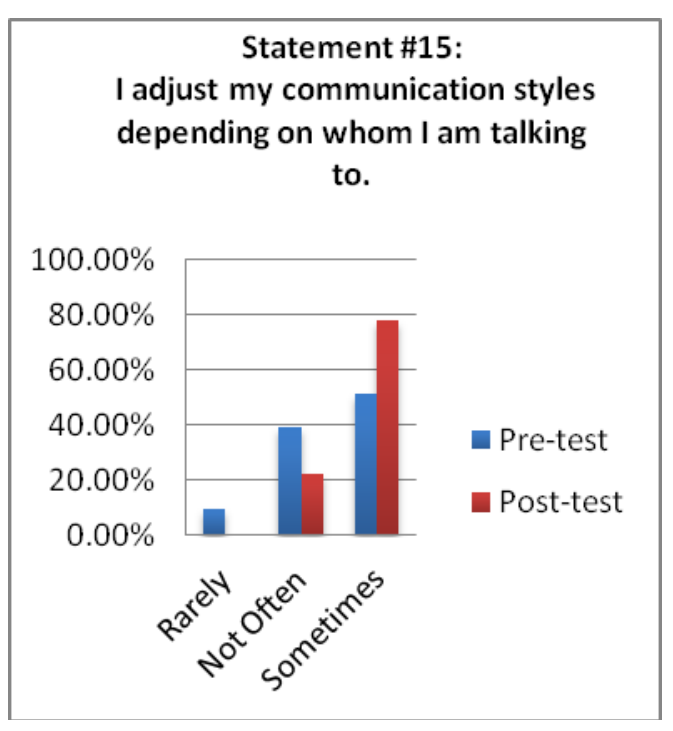

Responses to the open-ended questions added to the post-course survey:

1) In a few words, please reflect on the most important thing(s) you learned in this course.

$>$ Not to assert myself in a generally American way.

$>$ I learned more about my own cultural background and grew to appreciate it more so than I did before. I learned to appreciate aspects of different cultures now that I understand where the cultural differences come from. I have a lot more understanding.

$>$ I learned how important it is to know about different cultures' values and etiquette. It is important to know these so you know how to act around people of a different cultural background.

> I think that learning about different cultures is important for life situations like work, etc.

> I learned how to interact with people without offending them.

$>$ I learned that every culture has their own morals, values, and beliefs. The one thing we all have in common is to respect others and family is a big thing.

$>$ I learned a lot about my own cultural background, from the Cultural Journey Project. I also learned more than I already did about the people I interviewed for the final paper.

$>$ Be conscious of the people and cultural groups you talk to. Its easy to offend a people out of ignorance.

$>$ How to analyze and communicate with other cultures.

$>$ Acculturation, culture shock. Surprisingly never heard of these terms, but very easy to understand. Also, that the color of your skin shows where you come from. Ex. Black does not mean you have brown skin, it shows where your ancestors are from.

$>$ I have learned major differences and similarities between different cultures. I also learned many things I have never before.

$>$ How to speak to people in other cultures and what could be disrespectful to some people may not be to others. 
> I have learned to take the time to inquire about someone's culture, rather than brush it off.

> I have learned that more people consider themselves global citizens than I've known.

> I learned that cultural acceptance and tolerance is extremely important. All individuals have different cultural backgrounds and practice different values and beliefs. Understanding these differences is extremely important.

> I learned lots of information on all sorts of cultures all around the world as well as a deep understanding about language and culture shock.

$>$ I learned the differences in varying cultures and that none are better or worse than another. That discussing culture is not the same as stereotyping and that knowledge of a person's culture makes it much easier to understand them and where they are coming from.

$>$ Learning about the different cultures and how people acted due to their culture, opened my eyes to new ways of treating people. I understand how to be more comfortable with a person of a different culture.

$>$ I learned that it is important understand how to approach someone who is in a different culture than you. It is also important to know that no matter what culture someone is from everyone is very different as an individual. Not everyone is the same.

$>$ What I learned in this class is the broad understandings from different culture, their values, beliefs, ethics, etc.

$>$ Different cultures around the world, communication, traditions, gestures/body language. I learned cultures can be very different but also very similar to others.

$>$ I learned a lot of useful things in this class that make me more aware of others and their cultures. I have a better understanding and more approachable way.

$>$ Before this course, I believe I had a good understanding of what made all cultures different. What I learned most importantly is what makes us the same and how that can help us connect to others from all cultural backgrounds.

$>$ Culture is important to building a foundation of who we are, but not conducive to every aspect of our lives.

$>$ Re-learning the core values of other cultures has already benefitted me this semester.

$>$ I enjoyed seeing some of the same cultural values between groups.

$>$ The most important thing I learned was the different values that different cultures have.

$>$ I learned the true meaning of culture, and I learned that everyone has a culture.

$>$ I learned that is important to be respectful of other people's beliefs and values. People really value what they know to be true and no one should put down another person's views.

All 29 responses to this question were positive indicating that the students who responded to this question thought they had increased their cross-cultural competence, global awareness and cultural self-awareness as a result of taking this class. 
2) Did you learn what you hoped you would?

> Yes. This was a very interesting class and I learned something new everyday. I really enjoyed learning about all the different cultures and hearing from the guest speakers.

$>$ Yes

$>$ Yes, I learned the differences between a lot of cultures.

$>$ I think I have a pretty good understanding of different cultures so I am pleased.

> Yes, I have a better understanding of different cultures.

$>$ I learned a lot about people. In every class I have ever had many of my fellow classmates are just faces in the crowd that I will not see, or care about after the semester, however in this class I feel as if I have become close with everyone, even if I never spoke with them.

$>$ Yes, absolutely. This course was very interesting and informative.

$>$ Yes I did. I even have discussions about this class with my boyfriend and how I wish he still went here since he's a business major and I know this course would help him.

$>$ Yes, for the most part. I was not very knowledgeable with culture as it was, so I learned a lot.

$>$ Yes!

$>$ Yes!

$>$ Yes

$>$ Yes, I learned even more than I would have hoped.

$>$ Yes, I learned a lot of interesting things this semester.

> Yes, having all of the guest speakers was interesting to learn about different cultures.

$>$ Yes I did.

$>$ Yes, I wanted to learn about other cultures and I got plenty of information. Thank you!

$>$ Yes! Fun class!

$>$ Yes, and more. I believe that I have learned a lot.

$>$ Yes! Loved the class.

$>$ I learned much more than expected.

$>$ Yes this was a valuable course.

> Yes and more. I learned about other students in the class.

$>$ Yes I did.

All 24 responses to this question were positive indicating that the students felt they had learned what they hoped they would as a result of taking the class. 
Appendix 2. Survey tool

MyCAP (My Cultural Awareness Profile): Your Journey Towards Cultural And Global Awareness (Marx \& Moss, 2011).

DIMENSION 1: Exploring the Global Context

Reflect on your knowledge about the global context...

Circle the responses that best represent your views.

1) I am knowledgeable about global and international issues.

Disagree Somewhat Disagree Somewhat Agree

2) I read or watch international newspapers, TV programs, and/or movies.

Rarely Not Often Sometimes

3) Globalization has impacted my life.

Disagree Somewhat Disagree Somewhat Agree

4) I consider how choices I make in my life might have a global impact.

Rarely Not Often Sometimes

DIMENSION 2: Learning About Different Cultures

Reflect on your current understandings of culture and other cultural groups...

Circle the responses that best represent your views.

5) When I meet new people, I try to learn about their cultural backgrounds.

Disagree Somewhat Disagree Somewhat Agree

6) Talking about common cultural characteristics is different from stereotyping.

Disagree Somewhat Disagree Somewhat Agree

7) Culture is more about traditions, celebrations, and history than about core values.

Disagree Somewhat Disagree Somewhat Agree

DIMENSION 3: Knowing Ourselves as Cultural

Reflect on your own cultural identity...

Circle the responses that best represent your views.

8) I consider myself as being part of a particular culture.

Disagree Somewhat Disagree Somewhat Agree

9) My cultural identity does not really influence how I perceive the world and how I behave.

Disagree Somewhat Disagree Somewhat Agree

10) I have been in situations where I felt like a cultural outsider.

Rarely Not Often Sometimes 
11) I hardly ever talk about cultural beliefs, values, and traditions.

Disagree Somewhat Disagree Somewhat Agree

DIMENSION 4: Communicating Across Cultural Differences

Reflect on your current intercultural communication skills...

Circle the responses that best represent your views.

12) I am comfortable talking with people from other cultural groups.

Disagree Somewhat Disagree Somewhat Agree

13) In any job situation, it is helpful to learn about the cultural background of my co-workers.

Disagree Somewhat Disagree Somewhat Agree

14) I notice that people from other cultures use different gestures and body language when they talk.

Rarely Not Often Sometimes

15) I adjust my communication styles depending on whom I am talking to.

Rarely Not Often Sometimes

\section{Copyright Disclaimer}

Copyright for this article is retained by the author(s), with first publication rights granted to the journal.

This is an open-access article distributed under the terms and conditions of the Creative Commons Attribution license (http://creativecommons.org/licenses/by/3.0/). 